\title{
Transplantation Research and Medicine
}

REVIEW ARTICLE

\section{Strategies in Preventing Diabetes after Pancreatectomy Using Islet Auto- and Allo-Transplantation}

\author{
Tori Tucker ${ }^{1}$, Kevin Labadie ${ }^{1}$, Christopher Kopan ${ }^{1}$, Michael Alexander $^{1}$ and Jonathan RT Lakey ${ }^{1,2 *}$ \\ ${ }^{1}$ Department of Surgery, University of California Irvine, Orange, California, USA \\ ${ }^{2}$ Department of Biomedical Engineering, University of California Irvine, Irvine, California, USA
}

*Corresponding author: Jonathan RT Lakey, Professor, Department of Surgery, and Biomedical Engineering, Director of Clinical Islet Program, University of California, Irvine, California, USA, Tel: +1-949-824-8022, Fax: +1-714-456-6188, E-mail: jlakey@uci.edu

\begin{abstract}
Over the years, pancreatectomy has been the primary treatment for chronic pancreatitis. Since the 1970s, total pancreatectomy has been shown to be effective at relieving pain that was experienced due to chronic pancreatitis. However, total pancreatectomy alone has the significant side effect of post-surgical diabetes. To treat post-pancreatectomy diabetes, total pancreatectomy was combined with Islet Autotransplantation (TP-IAT), which resulted in a much lower mortality rate compared to total pancreatectomy alone. Such operations require an expertise in islet isolation techniques, and thus this procedure is not widely performed.

Since 2000, TP-IAT success has continued to increase. Improvement in islet isolation yield, better transplant techniques, and changes to post-operative care, have improved the islet engraftment and long-term survival rate. The Edmonton protocol, introduced in 2000 , offers the option of islet allograft to complement total pancreatectomy. This protocol uses improved immunosuppressive regimens to improve islet allograft tolerance and accomplished higher rate of insulin independence. This advance led to improved clinical outcome after TP-IAT, including islet graft success after transplantation, reduction in narcotic use, pain, and improvement in quality of life.

In this paper, we evaluated the history and advances of clinical islet transplant post-pancreatectomy. We also evaluated alternative transplant sites that are currently explored for islet graft, which are expected to offer improved islet engraftment and survival, and improved islet graft function.
\end{abstract}

\section{Keywords}

Pancreatitis, Pancreatectomy, Diabetes, Islet autotransplantation, Islet allograft

\section{Introduction}

Pancreatitis is the seventh most commonly diagnosed digestive disease in the United States, with rising ambulatory care visits and hospitalizations rate [1]. Chronic pancreatitis is much less common than the acute form, with only 5-14 new cases and a prevalence of about 50 chronic cases per 100,000 pancreatitis cases annually [2]. Despite its low prevalence, chronic pancreatitis contributes to significant morbidity and mortality that presents formidable challenges to patients, physicians and the healthcare system. There are several etiologies for chronic pancreatitis, with excessive alcohol consumption being the most common in the United States of America, followed by biliary duct obstruction by stones, tumors or pseudocysts, pancreas divisum, hypertriglyceridemia, autoimmune and familial pancreatitis [3]. The clinical manifestations of chronic pancreatitis are broad, including variable exocrine and endocrine insufficiency, and pain that is often debilitating and associated with poor quality of life $[4,5]$. There are several hypotheses for the pathophysiology of the pain, with one explanation positing an increase in ductal and interstitial pressures inducing local ischemia due to peri-pancreatic scarring that is perceived as pain through complex central and peripheral nervous inputs [6].

There is currently a variety of pharmacologic, endoscopic and surgical therapeutic options used to alleviate pain in chronic pancreatitis. Surgical interventions

Citation: Tucker T, Labadie K, Kopan C, Alexander M, Lakey JRT (2017) Strategies in Preventing Diabetes after Pancreatectomy Using Islet Auto- and Allo-Transplantation. Int J Transplant Res Med 3:029. doi. org/10.23937/2572-4045.1510029

Received: November 26, 2016: Accepted: May 12, 2017: Published: May 15, 2017

Copyright: (c) 2017 Tucker T, et al. This is an open-access article distributed under the terms of the Creative Commons Attribution License, which permits unrestricted use, distribution, and reproduction in any medium, provided the original author and source are credited. 
include partial pancreatic resections for predominantly localized pancreatic inflammation and pancreatic decompression procedures for large-duct obstruction [710]. These operations have been demonstrated to be safe, with a mortality of less than $2 \%$, and capable of achieving sustained pain relief in $80-90 \%$ of patients $[11,12]$. However, this treatment may be ineffective for patients who have diffuse disease or focal disease that is not suitable for decompression [13]. In the subset of patients with intractable pain and no other feasible treatment option, a total pancreatectomy is the only effective modality that can help achieve long-lasting pain relief $[14,15]$.

Total pancreatectomy for chronic pancreatitis was first reported in the 1960s and offers hope for patients who have exhausted, or are not amenable to, more conservative medical and surgical therapies [16]. However, total pancreatectomy alone has been shown to have significant morbidity and mortality [17]. It results in total pancreatic endocrine and exocrine deficiency associated with a variety of deleterious metabolic complications including those directly related to postsurgical diabetes $[18,19]$. Gall, et al. reported long term follow up in 117 patients who underwent total pancreatectomy for chronic pancreatitis reporting $19.1 \%$ mortality at 6.5 years with many late deaths caused by hypoglycemia [20]. In the 1970s, Najarian, et al. described the total pancreatectomy with islet autotransplantation (TP-IAT) in which pancreatic islets were isolated from the harvested organ and infused into the portal vein to attenuate the postsurgical diabetes [21]. The goal of the procedure is to relieve pain of chronic pancreatitis by removing the entire organ, while preserving the insulin-producing beta cell mass that will afford independence from exogenous insulin.

As of 2015, total pancreatectomy with islet autotransplantation (TP-IAT) is performed at 15 academic centers and nearly 1,000 procedures have been reported in the literature $[22,23]$. TP-IAT has been proven to be safe, with an operative mortality of $2 \%$ in several studies, and effective at relieving pain, improving quality of life and achieving insulin independence in up to a third of patients [24-26]. The procedure requires expertise in islet isolation techniques, and it is not widely performed. To increase access to this technology, "remote" TP-IAT has been reported; a situation where the pancreatectomy is performed at one site and the isolation is conducted at another [27]. The procedure has garnered significant interest in the last decade. There is increasing research effort focused on improving islet isolation, increasing yield and improving engraftment and long-term survival with clinical trials, with the potential to expand this procedure for benign and malignant pancreatic cancers [28].

\section{History of Pancreatectomy as Treatment for Pancreatitis}

Pancreatectomy has been an important treatment for patients suffering from chronic pancreatitis for decades $[17,29]$. Several published works in the late 1970 s demonstrated the effectiveness of Total Pancreatectomy (TP) for the amelioration of intractable pain experienced by those with chronic pancreatitis $[17,29,30]$. It has since been accepted as the best treatment option for patients who have exhausted or are not amenable to more conservative medical or surgical therapies. TP is considered a therapy of last resort because it is associated with significant long-term metabolic effects [19], with all patients becoming dependent on exogenous insulin to maintain glucose homeostasis [31]. A summary of these findings is provided in Table 1.

\section{Promises in Endocrine Replacement Therapy us- ing Islet Transplantation}

The first joint kidney and pancreas transplant was performed by Drs. Kelly and Lillehei at the University of Minnesota in 1966 [32]. The initial success of pancreas transplantation was poor, with only one of fourteen patients in the initial series surviving with a functioning

Table 1: Summary of past studies of partial and total pancreatectomy for treatment of pancreatitis.

\begin{tabular}{|c|c|c|c|c|}
\hline Patient ages & Trial period & Country & Reference & Results \\
\hline Not Reported & $1952-1976$ & United States of America & [17] & $\begin{array}{l}8 \text { of } 14 \text { surviving patients (from an initial } 26 \text { ) did not have } \\
\text { abdominal pain post pancreatectomy. However, the } \\
\text { surgery was found to produce many complications. }\end{array}$ \\
\hline $4-67$ & $1955-1975$ & United States of America & [29] & $\begin{array}{l}9 \text { of } 19 \text { patients were cured of their abdominal pain and } \\
\text { able to return to work post pancreaticoduodenectomy. }\end{array}$ \\
\hline $\begin{array}{l}\text { Average: } \\
34 \text { (men) } \\
39 \text { (women) }\end{array}$ & $1979-1986$ & England & [30] & $\begin{array}{l}19 \text { of } 29 \text { patients were cured of their abdominal pain, } \\
\text { post total pancreatectomy. The remaining } 10 \text { patients } \\
\text { still had pain that was less severe, often, and of shorter } \\
\text { duration. }\end{array}$ \\
\hline Average: 40 & $1998-2008$ & United States of America & [25] & $\begin{array}{l}30 \text { patients were evaluated after total pancreatectomy } \\
\text { and islet cell transplantation. Mean pain score dropped } \\
\text { from } 8( \pm 1.7) \text { to } 2.7( \pm 2.9) .85 \% \text { of patients became } \\
\text { insulin dependent. }\end{array}$ \\
\hline Average: 36.5 & $2002-2012$ & United States of America & [26] & $\begin{array}{l}84 \text { patients underwent total pancreatectomy and islet cell } \\
\text { autotransplantation. All but } 6 \text { patients decreased their } \\
\text { narcotics usage, and } 49 \text { ceased their narcotics use for } \\
\text { pain management. }\end{array}$ \\
\hline
\end{tabular}


graft at one year [33]. Around this time, pioneering efforts by Dr. Paul Lacy demonstrated the efficacy of intra-ductal enzymatic digestion in the isolation of pancreatic islet cells for transplantation [34]. Combined with advances in gradient purification technology, Dr. Lacy's work resulted in the first reported islet cell implant into diabetic rats in 1972 [35].

For patients with pancreatitis, the success rate of autotransplantation is primarily based on the number of islets remaining after the patient has undergone a total pancreatectomy in order to determine patient insulin independence. One major problem patients undergoing a total pancreatectomy face is the duration of chronic pancreatitis which could affect islet yield. A study that was conducted from Sutherland, et al. from the University of Minnesota have demonstrated islet yields < $2,500 \mathrm{IEQ} / \mathrm{kg}$ after a pancreatectomy followed by an autotransplant leads to a proportional decrease in insulin independence [36]. In a second study from Gruessner, et al. it was further demonstrated that in order to become insulin-independent and maintain normal glycemic control, islet yield must exceed $>2,500 \mathrm{IEQ} / \mathrm{kg}$. However, patients who had undergone previous surgeries had varying degrees of insulin-independence such as Whipple procedure $(100 \%)$, Puestow $(18 \%)$, distal pancreatectomy $(40 \%)$, and no other procedures $(80 \%)$ [37]. Patients who were partially insulin-independent had to maintain normal glycemic levels by a single injection of long-lasting insulin per day.

Allotransplantations are important for patients who cannot undergo autotransplants if they have had a longer duration of pancreatitis or have undergone other surgical procedures that could potentially yield a lower islet IEQ. Failure to transplant a sufficient quantity of islets could likely result in exogenous insulin dependence. Furthermore, some patients have severe loss of islets after a total pancreatectomy that $>2,500 \mathrm{IEQ} / \mathrm{kg}$ of islets is near impossible to achieve due to the condition of the patient. Therefore, most patients rely on allotransplantations from human donors. After demonstrating promise as an Endocrine Replacement Therapy in animals, islet cell allograft transplantation for the treatment of diabetes mellitus was first attempted in humans in the mid-1970s. By 1980, 73 islet allotransplantation procedures have been done in 68 patients. Unfortunately, these initial attempts were largely unsuccessful with only four of the recipients achieving insulin independence for any length of time [33]. It was unclear whether the allografts failed from host immune rejection or from technical limitations. In the initial attempts, islet cells were highly purified yielding small volumes for transplant that may have contributed to technical failure. Investigators soon discovered that it was safe and effective to transplant semi-purified islets in large animals with the benefit of achieving higher islet cell yields [38-41]. Other pharmacologic innovations at the time reduced exocrine tissue and enzyme content, lessening the deleterious effect of exocrine material while maintain endocrine mass [42].

A study by Tekin, et al. from the University of Chicago utilized the Edmonton Protocol for pancreatic islet allotransplantation of 9 patients with brittle type one diabetes. The 4 patients that completed the study received $7400 \mathrm{IEQ} / \mathrm{kg}$ per dose, and remained insulin-independent for a minimum of 5 years from their first islets infusion and maintained a HbA1c below 6.1 [43]. However, while allografts have become a possible treatment for patients with pancreatitis and type one diabetes, patients are still required to take immunosuppressants, which come with their own side effects [43].

These techniques proved to be beneficial in human transplantation, however the underlying question of whether islet allograft failures were technical or secondary to immune rejection still remained. To answer this question, investigators at the University of Minnesota in 1977 successfully achieved insulin independence after they transplanted the patient's own islets following a near total pancreatectomy for chronic pancreatitis. This obviated the possibility of immune rejection, and importantly, demonstrated the technical feasibility of islet transplantation in humans [21].

After several years of performing the procedure, investigators convened in Lyon France in March 1980 and developed a comprehensive bibliography of the world's first published cases were reported in the new Registry in the Proceedings of the Symposium on Pancreas Transplantation. 58 islet autotransplantations after > $90 \%$ pancreatectomy had been performed with $30 \%$ of patients achieving insulin independence. Only twelve patients had total pancreatectomy while the remaining underwent near total (>90\%) pancreatectomies. The total pancreatectomy cohort experienced a much lower rate of insulin independence in comparison to the near-total pancreatectomy group indicating that the pancreatic remnant played an important role in insulin production. The procedure was considered inefficient but nonetheless showed promise of autoislet cell transplantation in achieving insulin independence after total or near total pancreatectomy $[33,44]$.

\section{Recent Advances in Islet Transplantation}

\section{Problems with Early Islet Transplant}

Early experiences with islet cell transplantation were found to be associated with life threatening complications due to the nature of the poorly purified islet infusions. Episodes of acute portal hypertension and Disseminated Intravascular Coagulation (DIC) with subsequent diffuse hemorrhage were reported in the initial patients receiving IAT [45]. In 1980, Mehigan, et al. demonstrated increased portal pressures in dogs after IAT with peak portal pressures of $43.2 \mathrm{~cm} \mathrm{H}_{2} \mathrm{O}$ accompa- 
nied by marked hematologic abnormalities consistent with DIC [46]. All five dogs died from intraperitoneal bleeding within 10 hours of operation and were found to have pancreatic tissue and thrombus occluding the main portal vein at autopsy. The supernatant of the islet cell infusion volume was found to have high levels of thromboplastin released during the islet cell isolation process and the likely precipitant of thrombus formation.

After the initial experience in the late 1970s, there were limited reports of islet cell autotransplantation for the next 2 decades [47]. Investigators were facing several challenges at the time, including surgical complications, as well as suboptimal isolation and purification methods. To obtain sufficient islet cell mass to achieve a physiologic response, several donor pancreata were required, which compromised autotransplantation feasibility [48]. The following years were defined by progress in isolation and purification methodology that culminated in the development of the Ricordi method in 1988, an automated method for isolation of human pancreatic islets [49]. This procedure resulted in significantly increased islet cell yield and was adopted by most research centers performing islet cell transplants.

\section{The beginning of the Edmonton Protocol in $\mathbf{2 0 0 0}$}

Interest in islet transplantation was further galvanized in $\mathbf{2 0 0 0}$ when the Edmonton Protocol for islet cell allotransplantation was introduced from the University of Alberta (Figure 1). The protocol described a novel immunosuppressive regimen of sirolimus, low-dose tacrolimus and daclizumab while sparing the use of diabetogenic corticosteroids [50]. The initial trial of this immunosuppressive regimen for seven type one diabetics demonstrated complete insulin independence at one year. To explore the reproducibility of these findings, an international trial of the Edmonton Protocol with 36 patients at nine international sites was conducted [51]. In this trial, the protocol was confirmed to successfully restore glycemic stability in type 1 diabetics but was found to be short-lived with only $31 \%$ of patients remained insulin-independent at two years. An important outcome of this and a larger multicenter study that followed was the recognition of improved outcomes in higher volume centers [51]. Previous experience with islet cell isolation and transplantation was a significant predictor of achieving insulin independence. The primary endpoint of this study, achieving insulin independence at 1 year, was reached in $67 \%$ of cases at high volume centers (more than four or more transplantations in the preceding two years) in comparison with only $22 \%$ of cases in low volume centers. This finding led to collaboration among institutions to share isolation facilities in effort to expand access to treatment [27]. In the spirit of this collaboration, National Institute of Health has recently sponsored a Clinical Islet Transplantation consortium
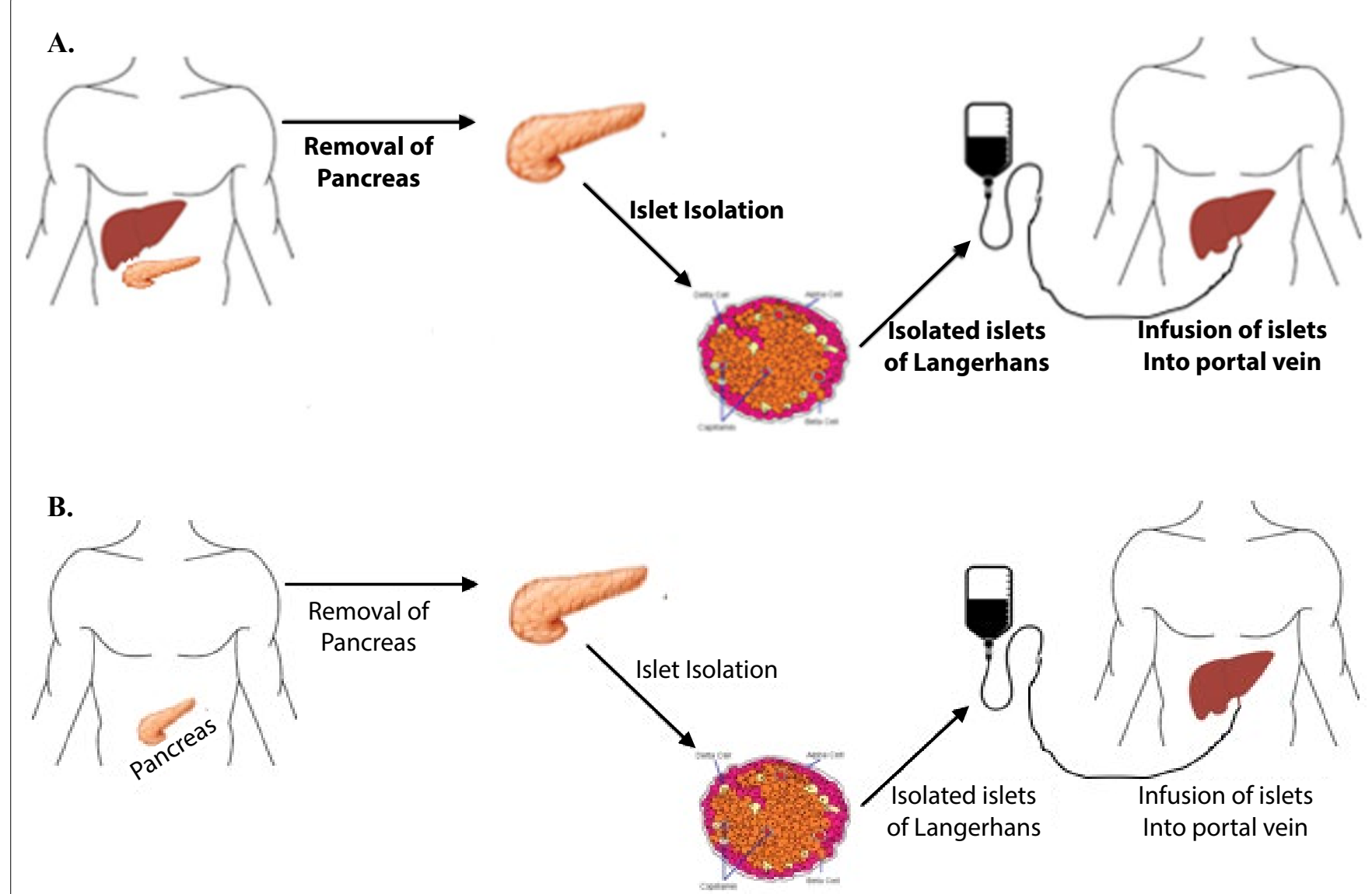

Figure 1: Diagram of the procedure for $A$ ) islet autograft from the same patient, compared to $B$ ) islet allograft from cadaveric organ donor to recipient. 
Table 2: Summary of advantages and disadvantages of various transplant sites that have been evaluated for human islet transplant.

\begin{tabular}{|c|c|c|}
\hline Site & Advantage & Disadvantage \\
\hline Intraliver & Good vascular supply. & $\begin{array}{l}\text { Vessel aneurysm, thrombosis. } \\
\text { Acute steatosis. } \\
\text { Incorrect inhibition of glucagon release of transplanted islets. } \\
\text { Limited volume of islets possible. }\end{array}$ \\
\hline Spleen & $\begin{array}{l}\text { Better islet survival and success rate of } \\
\text { diabetes reversal in animal models. } \\
\text { Avoids hyperinsulinemia. }\end{array}$ & Abnormal glucagon response during hypoglycemic eposides. \\
\hline Omentum & $\begin{array}{l}\text { Easy surgical accessibility. } \\
\text { Can accommodate larger volume of islets. } \\
\text { Avoids hyperinsulinemia. }\end{array}$ & Abnormal glucagon response during hypoglycemic eposides. \\
\hline Intramuscular & $\begin{array}{l}\text { Good vascularization in the absence of } \\
\text { suitable intraliver transplant. }\end{array}$ & $\begin{array}{l}\text { Limited volume of islets. } \\
\text { Limited evidence of long term success. }\end{array}$ \\
\hline Peritoneal cavity & $\begin{array}{l}\text { Very large capacity, especially for } \\
\text { encapsulated islet transplant. }\end{array}$ & $\begin{array}{l}\text { Delay in systemic insulin distribution. } \\
\text { Larger number of islets needed to provide blood glucose } \\
\text { control. }\end{array}$ \\
\hline Subcutaneous space & Easy to access. & $\begin{array}{l}\text { Limited data on non-encapsulated islet transplant. } \\
\text { Lack of good immediate vascular supply. }\end{array}$ \\
\hline
\end{tabular}

study, aimed at developing a common standard to follow across different islet isolation centers. Islets isolated under this study were successfully implanted in 48 patients with no adverse effects, thus illustrating the importance of a national standard on islet isolation to ensure good clinical outcome [52].

In addition to improved outcomes being linked to higher volume centers, several studies have been published examining various factors that predicted positive outcomes for TP-IAT [53-56]. Important outcomes that are most commonly measured after TP-IAT include postoperative islet graft survival and function, narcotic use, persistence pain, and changes to quality of life. The factors that have been found to be most influential of clinical outcomes include islet cell yield, transplant tissue volume [56], isolation and purification techniques [54], and duration of narcotic use and physical health prior to surgery. Low islet yield is the strongest independent risk factor for islet graft failure postoperatively [53]. Instant Blood-Mediated Inflammatory Reaction (IBMIR) was previously found to be common in recipient of islet allo- or xenograft, however, recent study showed its incidence in islet autograft as well, indicated by elevated c-peptide and Thrombin-Anti-Thrombin III Complex (TAT) in blood post-operatively. In the case of TP-IAT, the cytokine release leading to IBMIR may have occurred because of the surgery process itself [57]. Despite these chances for failure, TP-IAT has been found to be safe overall, with low mortality, morbidity, and a good rate of achieving insulin independence [58].

\section{Umbilical vein route of access for intraportal transplant}

The umbilical vein has been used in several transplants to access the portal vein system. One benefit of umbilical vein as a route for islet transplant is the possibility to monitor pressure of the portal vein for up to 5-days post transplantation [59].

Islets infused to the umbilical vein and islets infused to non-umbilical vein were used to compare metabolic results over time using a fasting glucose tolerance test for glycosylated haemoglobin, fasting and 2-hours after stimulation, and C-peptide. The results showed that the umbilical vein approach had no significant difference of postoperative metabolic function compared to non-umbilical vein approaches [59].

\section{The option of alternative sites for islet transplan- tation}

There are several complications associated with intrahepatic islet transplant through the portal vein. Intraportal islet infusion can trigger hepatic false aneurysm [60], portal vein thrombosis [61], and acute hepatic steatosis [62]. Recently, the intrahepatic location of islet transplantation has been suggested to be a potential cause for islet graft failure and increase in hypoglycemic incidence. One potential issue is that systemic hypoglycemia can stimulate liver to trigger glycogen metabolic breakdown, but the increase of local hepatic glucose incorrectly causes the $\alpha$-cells in the transplanted islets to be quiescent [63]. These factors can have significant negative impact on patient's health and the survival and function of the transplanted islets. As such, there has been interest in evaluating alternate sites for islet transplant after total pancreatectomy.

In addition, previous studies have shown that the spleen is a better suited site for islet survival and the reversal of diabetes. Meanwhile, the omentum is easily accessible and can accommodate larger tissue volume than the liver, potentially allowing higher dose of islet for transplant [64]. The advantages and disadvantages of the various transplant sites are summarized in Table 2 , and will be elaborated on as follows.

\section{Spleen and omentum}

The lack of islets after total pancreatectomy impacts not only the lack of $\beta$-cell response, but also the $\alpha$-cell response to hypoglycemia. This concern on pancreatic 
regulation in response to hypoglycemic events following islet transplantation is still not resolved even after the Edmonton protocol.

One study utilizing spleen and omental pouch as sites for islet transplantation, suggests that both sites may avoid the issues of hyperinsulinemia ensuing post intrahepatic islet transplant [64]. However, neither site managed to show evidence of normal glucagon response in hypoglycemic incidence [64].

\section{Intramuscular}

One study demonstrates the first therapeutic attempt to implant islets intramuscularly in a 7-year-old girl who experienced hereditary pancreatitis and underwent a complete pancreatectomy [65]. Previous studies have normally used the intramuscular site for a shortterm islet engraftment and survival, because intramuscular islet transplants demonstrated very limited long term success rates. The intramuscular site was chosen in this study due to the patient's unhealthy pancreatic tissue microenvironment for the enablement of beta-cells to survive and produce insulin under normal conditions, if they were to be transplanted into the liver [65].

The intramuscular islet transplant post pancreatectomy decreased the patient's exogenous insulin need, while maintaining a normal HbA1c of $4.5 \%$. In addition, insulin response was confirmed during glucose tolerance tests [65].

\section{Peritoneal cavity}

The freedom from volume constraint for transplant placement in the peritoneal cavity makes it an attractive choice for both free and encapsulated islet transplant [66]. Clinically, the peritoneal cavity is currently undergoing trials mainly for encapsulated islets [67]. There's a delay in systemic insulin distribution from islets placed in the peritoneal cavity [68], and a significantly larger number of islets is needed to result in cure when compared to intraportal transplantation [66].

\section{Subcutaneous space}

There are only a limited amount of clinical studies in islet transplant in the subcutaneous space. These studies have focused mainly on the use of protective enclosure devices, such as individually encapsulated islets [69] or a macroencapsulation device [70]. Currently, no study has reported the use of subcutaneous space for transplant of non-encapsulated autologous islets [66].

\section{Conclusion}

The improvements of islet isolation and transplantation methods, as well as improvements in immunosuppression treatment for allotransplantation, have increased the attractiveness of islet transplant after total pancreatectomy to prevent diabetes and hypoglycemic episodes. These procedures have been found to be safe overall, with low mortality and morbidity, provided the patient received sufficient dose of islets and maintained the transplanted islet survival.

\section{Acknowledgement}

We gratefully acknowledge the University of California Irvine, Department of Surgery, and the Sue and Bill Gross Research Center, for their support toward the writing of this publication.

\section{References}

1. Everhart JE, Ruhl CE (2009) Burden of digestive diseases in the United States Part III: Liver, biliary tract, and pancreas. Gastroenterology 136: 1134-1144.

2. Yadav D, Timmons L, Benson JT, Dierkhising RA, Chari ST (2011) Incidence, prevalence, and survival of chronic pancreatitis: a population-based study. Am J Gastroenterol 106: 2192-2199.

3. Cote GA, Yadav D, Slivka A, Hawes RH, Anderson MA, et al. (2011) Alcohol and smoking as risk factors in an epidemiology study of patients with chronic pancreatitis. Clin Gastroenterol Hepatol 9: 266-273.

4. Andren-Sandberg A, Hoem D, Gislason H (2002) Pain management in chronic pancreatitis. Eur J Gastroenterol Hepatol 14: 957-970.

5. Ohayon MM, Schatzberg AF (2010) Chronic pain and major depressive disorder in the general population. J Psychiatr Res 44: 454-461.

6. Morgan K, Owczarski SM, Borckardt J, Madan A, Nishimura M, et al. (2012) Pain control and quality of life after pancreatectomy with islet autotransplantation for chronic pancreatitis. J Gastrointest Surg 16: 129-133.

7. Bliss LA, Yang CJ, Eskander MF, de Geus SW, Callery MP, et al. (2015) Surgical management of chronic pancreatitis: current utilization in the United States. HPB (Oxford) 17: 804-810.

8. Frey CF, Amikura K (1994) Local resection of the head of the pancreas combined with longitudinal pancreaticojejunostomy in the management of patients with chronic pancreatitis. Ann Surg 220: 492-504.

9. Frey CF, Smith GJ (1987) Description and rationale of a new operation for chronic pancreatitis. Pancreas 2: 701-707.

10. Puestow CB, Gillesby WJ (1958) Retrograde surgical drainage of pancreas for chronic relapsing pancreatitis. AMA Arch Surg 76: 898-907.

11. Cahen DL, Gouma DJ, Nio Y, Rauws EA, Boermeester MA, et al. (2007) Endoscopic versus surgical drainage of the pancreatic duct in chronic pancreatitis. N Engl J Med 356: 676-684.

12. Holmberg JT, Isaksson G, Ihse I (1985) Long term results of pancreaticojejunostomy in chronic pancreatitis. Surg Gynecol Obstet 160: 339-346.

13. Gachago C, Draganov PV (2008) Pain management in chronic pancreatitis. World J Gastroenterol 14: 3137-3148.

14. Sutherland DE, Radosevich DM, Bellin MD, Hering BJ, Beilman GJ, et al. (2012) Total pancreatectomy and islet autotransplantation for chronic pancreatitis. J Am Coll Surg 214: 409-424.

15. Schmulewitz N (2011) Total pancreatectomy with autologous islet cell transplantation in children: making a difference. Clin Gastroenterol Hepatol 9: 725-726. 
16. Warren KW, Poulantzas JK, Kune GA (1966) Life after total pancreatectomy for chronic pancreatitis: clinical study of eight cases. Ann Surg 164: 830-834.

17. Braasch JW, Vito L, Nugent FW (1978) Total pancreatectomy of end-stage chronic pancreatitis. Ann Surg 188: 317322.

18. Berney T, Rudisuhli T, Oberholzer J, Caulfield A, Morel P (2000) Long-term metabolic results after pancreatic resection for severe chronic pancreatitis. Arch Surg 135: 11061111.

19. lino S (1992) [Japanese clinical statistical data of patients with hepatitis B]. Nihon Rinsho 50: S602-S612.

20. Gall FP, Muhe E, Gebhardt C (1981) Results of partial and total pancreaticoduodenectomy in 117 patients with chronic pancreatitis. World J Surg 5: 269-275.

21. Najarian JS, Sutherland DE, Matas AJ, Goetz FC (1979) Human islet autotransplantation following pancreatectomy. Transplant Proc 11: 336-340.

22. Kesseli SJ, Smith KA, Gardner TB (2015) Total pancreatectomy with islet autologous transplantation: the cure for chronic pancreatitis? Clin Transl Gastroenterol 6: e73.

23. Bellin MD, Gelrud A, Arreaza-Rubin G, Dunn TB, Humar A, et al. (2015) Total pancreatectomy with islet autotransplantation: summary of an NIDDK workshop. Ann Surg 261: 21-29.

24. Ong SL, Gravante G, Pollard CA, Webb MA, Illouz S, et al. (2009) Total pancreatectomy with islet autotransplantation: an overview. HPB (Oxford) 11: 613-621.

25. Mokadem M, Noureddine L, Howard T, McHenry L, Sherman S, et al. (2016) Total pancreatectomy with islet cell transplantation vs intrathecal narcotic pump infusion for pain control in chronic pancreatitis. World J Gastroenterol 22: 4160-4167.

26. Wilson GC, Sutton JM, Smith MT, Schmulewitz N, Salehi $\mathrm{M}$, et al. (2015) Total pancreatectomy with islet cell autotransplantation as the initial treatment for minimal-change chronic pancreatitis. HPB (Oxford) 17: 232-238.

27. Tai DS, Shen N, Szot GL, Posselt A, Feduska NJ, et al. (2015) Autologous islet transplantation with remote islet isolation after pancreas resection for chronic pancreatitis. JAMA Surg 150: 118-124.

28. Tanhehco YC, Weisberg S, Schwartz J (2016) Pancreatic islet autotransplantation for nonmalignant and malignant indications. Transfusion 56: 761-770.

29. Frey CF, Child CG, Fry W (1976) Pancreatectomy for chronic pancreatitis. Ann Surg 184: 403-413.

30. Linehan IP, Lambert MA, Brown DC, Kurtz AB, Cotton PB, et al. (1988) Total pancreatectomy for chronic pancreatitis. Gut 29: 358-365.

31. Najarian JS, Sutherland DE, Baumgartner D, Burke B, Rynasiewicz JJ, et al. (1980) Total or near total pancreatectomy and islet autotransplantation for treatment of chronic pancreatitis. Ann Surg 192: 526-542.

32. Kelly WD, Lillehei RC, Merkel FK, Idezuki Y, Goetz FC (1967) Allotransplantation of the pancreas and duodenum along with the kidney in diabetic nephropathy. Surgery 61 : 827-837.

33. Sutherland DE, Goetz FC, Najarian JS (1981) Review of world's experience with pancreas and islet transplantation and results of intraperitoneal segmental pancreas transplantation from related and cadaver donors at Minnesota.
Transplant Proc 13: 291-297.

34. Lacy PE, Kostianovsky M (1967) Method for the isolation of intact islets of Langerhans from the rat pancreas. Diabetes 16: 35-39.

35. Ballinger WF, Lacy PE (1972) Transplantation of intact pancreatic islets in rats. Surgery 72: 175-186.

36. Takita M, Lara LF, Naziruddin B, Shahbazov R, Lawrence MC, et al. (2015) Effect of the Duration of Chronic Pancreatitis on Pancreas Islet Yield and Metabolic Outcome Following Islet Autotransplantation. J Gastrointest Surg 19: 1236-1246.

37. Gruessner RW, Sutherland DE, Dunn DL, Najarian JS, Jie T, et al. (2004) Transplant options for patients undergoing total pancreatectomy for chronic pancreatitis. J Am Coll Surg 198: 559-567.

38. Schulak JA, Stuart FP, Reckard CR (1978) Physiologic aspects of intrasplenic autotransplantation of pancreatic fragments in the dog after 24 hours of cold storage. J Surg Res 24: $125-131$.

39. Kretschmer GJ, Sutherland DE, Matas AJ, Steffes MW, Najarian JS (1977) The dispersed pancreas: transplantation without islet purification in totally pancreatectomized dogs. Diabetologia 13: 495-502.

40. Kolb E, Ruckert R, Largiader F (1977) Intraportal and intrasplenic autotransplantation of pancreatic islets in the dog. Eur Surg Res 9: 419-426.

41. Mirkovitch V, Campiche M (1976) Successful intrasplenic autotransplantation of pancreatic tissue in totally pancreatectomised dogs. Transplantation 21: 265-269.

42. Sutherland DE, Matas AJ, Najarian JS (1978) Pancreatic islet cell transplantation. Surg Clin North Am 58: 365-382.

43. Tekin Z, Garfinkel MR, Chon WJ, Schenck L, Golab K, et al. (2016) Outcomes of Pancreatic Islet Allotransplantation Using the Edmonton Protocol at the University of Chicago. Transplant Direct 2: e105.

44. Valente U, Ferro M, Campisi C, Cataldi L, Fontana I, et al. (1980) Report of clinical cases of islet autotransplantation. Transplant Proc 12: 202-204.

45. Mittal VK, Toledo-Pereyra LH, Sharma M, Ramaswamy K, Puri VK, et al. (1981) Acute portal hypertension and disseminated intravascular coagulation following pancreatic islet autotransplantation after subtotal pancreatectomy. Transplantation 31: 302-304.

46. Mehigan DG, Bell WR, Zuidema GD, Eggleston JC, Cameron JL (1980) Disseminated intravascular coagulation and portal hypertension following pancreatic islet autotransplantation. Ann Surg 191: 287-293.

47. Agarwal A, Brayman KL (2012) Update on islet cell transplantation for type 1 diabetes. Semin Intervent Radiol 29: 90-98.

48. Sutherland DE, Steffes MW, Bauer GE, McManus D, Noe $\mathrm{BD}$, et al. (1974) Isolation of human and porcine islets of Langerhans and islet transplantation in pigs. J Surg Res 16: 102-111.

49. Ricordi C, Lacy PE, Finke EH, Olack BJ, Scharp DW (1988) Automated method for isolation of human pancreatic islets. Diabetes 37: 413-420.

50. Shapiro AM, Lakey JR, Ryan EA, Korbutt GS, Toth E, et al. (2000) Islet transplantation in seven patients with type 1 diabetes mellitus using a glucocorticoid-free immunosuppressive regimen. N Engl J Med 343: 230-238. 
51. Shapiro AM, Ricordi C, Hering BJ, Auchincloss H, Lindblad $\mathrm{R}$, et al. (2006) International trial of the Edmonton protocol for islet transplantation. N Engl J Med 355: 1318-1330.

52. Ricordi C, Goldstein JS, Balamurugan AN, Szot GL, Kin T, et al. (2016) National Institutes of Health-Sponsored Clinical Islet Transplantation Consortium Phase 3 Trial: Manufacture of a Complex Cellular Product at Eight Processing Facilities. Diabetes 65: 3418-3428.

53. Chinnakotla S, Beilman GJ, Dunn TB, Bellin MD, Freeman ML, et al. (2015) Factors Predicting Outcomes After a Total Pancreatectomy and Islet Autotransplantation Lessons Learned From Over 500 Cases. Ann Surg 262: 610-622.

54. Naziruddin B, Matsumoto S, Noguchi H, Takita M, Shimoda $M$, et al. (2012) Improved pancreatic islet isolation outcome in autologous transplantation for chronic pancreatitis. Cell Transplant 21: 553-558.

55. Harris H (2012) Systematic review of total pancreatectomy and islet autotransplantation for chronic pancreatitis $(\mathrm{Br} \mathrm{J}$ Surg 2012; 99: 761-766). Br J Surg 99: 767.

56. Matsumoto S, Takita M, Shimoda M, Sugimoto K, Itoh T, et al. (2012) Impact of tissue volume and purification on clinical autologous islet transplantation for the treatment of chronic pancreatitis. Cell Transplant 21: 625-632.

57. Naziruddin B, Iwahashi S, Kanak MA, Takita M, Itoh T, et al. (2014) Evidence for instant blood-mediated inflammatory reaction in clinical autologous islet transplantation. Am J Transplant 14: 428-437.

58. Fazlalizadeh R, Moghadamyeghaneh Z, Demirjian AN, Imagawa DK, Foster CE, et al. (2016) Total pancreatectomy and islet autotransplantation: $A$ decade nationwide analysis. World J Transplant 6: 233-238.

59. Pollard C, Gravante G, Webb M, Chung WY, Illouz S, et al. (2011) Use of the recanalised umbilical vein for islet autotransplantation following total pancreatectomy. Pancreatology 11: 233-239.

60. Onaca N, Naziruddin B, Randall HB, Meler JD, Sanchez $E Q$, et al. (2009) False aneurysm of a hepatic artery branch complicating intrahepatic islet transplantation. Transpl Int 22: 663-666.
61. Kawahara T, Kin T, Kashkoush S, Gala-Lopez B, Bigam $\mathrm{DL}$, et al. (2011) Portal vein thrombosis is a potentially preventable complication in clinical islet transplantation. Am J Transplant 11: 2700-2707.

62. Jackson S, Mager DR, Bhargava R, Ackerman T, Imes S, et al. (2013) Long-term follow-up of hepatic ultrasound findings in subjects with magnetic resonance imaging defined hepatic steatosis following clinical islet transplantation: a case-control study. Islets 5: 16-21.

63. Robertson RP (2016) Spontaneous Hypoglycemia After Islet Transplantation: The Case For Using Non-Hepatic Sites. J Clin Endocrinol Metab 101: 3571-3574.

64. Gustavson SM, Rajotte RV, Hunkeler D, Lakey JR, Edgerton DS, et al. (2005) Islet auto-transplantation into an omental or splenic site results in a normal beta cell but abnormal alpha cell response to mild non-insulin-induced hypoglycemia. Am J Transplant 5: 2368-2377.

65. Rafael E, Tibell A, Ryden M, Lundgren T, Savendahl L, et al. (2008) Intramuscular autotransplantation of pancreatic islets in a 7-year-old child: a 2-year follow-up. Am J Transplant 8: 458-462.

66. Cantarelli E, Piemonti L (2011) Alternative transplantation sites for pancreatic islet grafts. Curr Diab Rep 11: 364-374.

67. Calafiore R, Basta G, Luca G, Lemmi A, Montanucci MP, et al. (2006) Microencapsulated pancreatic islet allografts into nonimmunosuppressed patients with type 1 diabetes: first two cases. Diabetes Care 29: 137-138.

68. Pepper AR, Gala-Lopez B, Ziff O, Shapiro AM (2013) Revascularization of transplanted pancreatic islets and role of the transplantation site. Clin Dev Immunol 2013: 352315.

69. Calafiore R (1992) Transplantation of microencapsulated pancreatic human islets for therapy of diabetes mellitus. A preliminary report. ASAIO J 38: 34-37.

70. Scharp DW, Swanson CJ, Olack BJ, Latta PP, Hegre OD, et al. (1994) Protection of encapsulated human islets implanted without immunosuppression in patients with type I or type II diabetes and in nondiabetic control subjects. Diabetes 43: 1167-1170. 